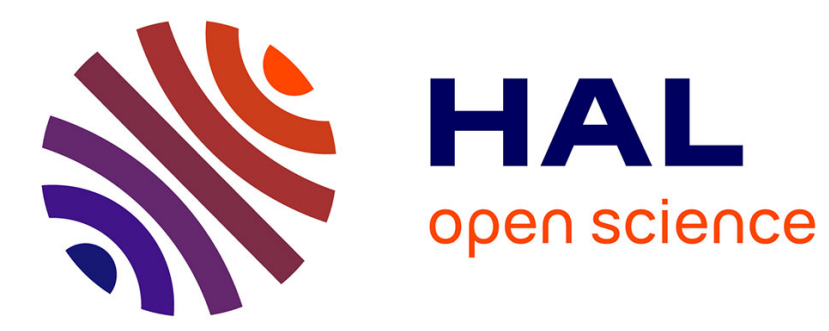

\title{
The Whodunit Challenge: Mobilizing the Crowd in India
}

\author{
Aditya Vashistha, Rajan Vaish, Edward Cutrell, William Thies
}

\section{To cite this version:}

Aditya Vashistha, Rajan Vaish, Edward Cutrell, William Thies. The Whodunit Challenge: Mobilizing the Crowd in India. 15th Human-Computer Interaction (INTERACT), Sep 2015, Bamberg, Germany. pp.505-521, 10.1007/978-3-319-22668-2_39. hal-01599880

\section{HAL Id: hal-01599880 \\ https://hal.inria.fr/hal-01599880}

Submitted on 2 Oct 2017

HAL is a multi-disciplinary open access archive for the deposit and dissemination of scientific research documents, whether they are published or not. The documents may come from teaching and research institutions in France or abroad, or from public or private research centers.
L'archive ouverte pluridisciplinaire HAL, est destinée au dépôt et à la diffusion de documents scientifiques de niveau recherche, publiés ou non, émanant des établissements d'enseignement et de recherche français ou étrangers, des laboratoires publics ou privés. 


\title{
The Whodunit Challenge: Mobilizing the Crowd in India
}

\author{
Aditya Vashistha ${ }^{1}$, Rajan Vaish ${ }^{2}$, Edward Cutrell $^{3}$, and William Thies ${ }^{3}$ \\ ${ }^{1}$ University of Washington, Seattle, USA \\ adityav@cs.washington. edu \\ ${ }^{2}$ University of California, Santa Cruz, USA \\ rvaishecs.ucsc.edu \\ ${ }^{3}$ Microsoft Research India, Bangalore, India \\ \{cutrell, thies\}@microsoft. com
}

\begin{abstract}
While there has been a surge of interest in mobilizing the crowd to solve large-scale time-critical challenges, to date such work has focused on high-income countries and Internet-based solutions. In developing countries, approaches for crowd mobilization are often broader and more diverse, utilizing not only the Internet but also face-to-face and mobile communications. In this paper, we describe the Whodunit Challenge, the first social mobilization contest to be launched in India. The contest enabled participation via basic mobile phones and required rapid formation of large teams in order to solve a fictional my stery case. The challen ge encompassed 7,700 participants in a single day and was won by a university team in about 5 hours. To understand teams' strategies and experiences, we conducted 84 phone interviews. While the Internet was an important tool for most teams, in contrast to prior challenges we also found heavy reliance on personal networks and offline communication channels. We synthesize these findings and offer recommendations for future crowd mobilization challenges targeting low-income environments in developing countries.
\end{abstract}

Keywords: Crowdsourcing, crowd mobilization, HCI4D, ICT4D, India

\section{Introduction}

Recent years have witnessed the power of crowdsourcing as a tool for solving important societal challenges [1-4]. Of particular note are instances of crowd mobilization, where large groups of people work together in service of a common goal. A landmark demonstration of crowd mobilization is the DARPA Network Challenge, where teams competed to find 10 red balloons that were hidden across the United States [5]. The winning team found all the balloons in less than nine hours, utilizing a recursive incentive structure that rewarded participants both for joining the search as well as for growing the team [6]. Since then, mobilization exercises such as the Tag Challenge have shown that teams can locate people of interest across North America and Europe [7]. The MyHeartMap Challenge mapped over 1,500 defibrillators in Philadelphia County [8]. Authorities have also turned to crowd mobilization for help gathering intelligence surrounding the London riots [9] and the Boston Marathon 
bombings [10], though the results have not been without pitfalls [11] and controversy [12].

One limitation of prior crowd mobilization studies is that they have focused exclusively on North America and Europe, where Internet penetration is so high that most teams pursue purely online strategies. However, in other areas of the world, the Internet remains only one of several complementary channels for effective mobilization of crowd. For example, in India, $1.2 \%$ of households have broadband Internet access [13], but there are 929 million mobile subscribers, over 550 million viewers of television, and over 160 million listeners to radio [13, 14]. An SMS-based social network called SMS GupShup has 66 million subscribers in India [15]. Moreover, there is a rich oral tradition of conveying stories and information face-to-face. Environments such as the Indian railways - serving 175 million passengers every week [16] - provide fertile grounds for mobilizing crowds. India also has a unique social milieu, with its own social hierarchies, attitudes towards privacy [17], and trust in / responsiveness to various incentive schemes. In light of all these characteristics, it stands to reason that effective crowd mobilization in India would require broader and more inclusive techniques than in Western contexts.

To further explore the landscape of crowd mobilization in India, this paper reports on a new mobilization contest that was designed specifically for the Indian context. Dubbed the "Whodunit Challenge", the contest enabled participation through mobile phones instead of via the Internet. The contest offered a Rs. 100,000 (USD 1,667) prize $^{1}$ for solving a fictional mystery case, in which teams were asked to gather five pieces of information: Who, What, Where, When, and Why. To participate, an individual had to send a missed call ${ }^{2}$ to the contest phone number, which returned via SMS one of five phrases, each providing one of the pieces of information. Because some phrases were returned with low probability, and only one phrase was sent to each phone number irrespective of the number of missed calls received, participants needed to form teams of several hundred people in order to have a chance of winning.

The Whodunit Challenge attracted over 7,700 participants within the first day, and was won by a university team in just over five hours. To understand teams' experiences and strategies, we conducted 84 phone interviews, covering most individuals who submitted 3 or more phrases or who received phrases sent with low probability. While many of the winning teams did utilize the Internet to mobilize the crowd for finding phrases, we also uncovered interesting cases that relied mainly on face-to-face or mobile communication. Unlike previous crowd mobilization challenges, many successful teams relied only on personal networks, rather than trying to incentivize strangers to help them search for phrases. Members of these teams were usually unaware of (or unmotivated by) the cash award.

In the remainder of this paper, we describe the design rationale, execution strategy, and detailed evaluation of the Whodunit Challenge. To the best of our knowledge, this is the first paper to describe a large-scale crowd mobilization contest in a developing-

1 In this paper, we use an exchange rate of 1 USD $=$ Rs. 60 .

2 Sending a missed call refers to the practice of calling a number and hanging up before the recipient can answer [6] 
country context, exploring the portfolio of online and offline communication strategies that teams employed. We also offer recommendations to inform the design of future crowd mobilization challenges targeting low-income environments in developing countries.

\section{Related Work}

There is a vibrant conversation in the research community surrounding the future of crowd work [18]. Research that is most closely related to our work falls in two areas: crowd mobilization challenges and crowdsourcing in developing regions.

One of the most high-profile experiments in crowd mobilization was DARPA's Network Challenge, launched in 2009. By asking teams to find ten red balloons that were hidden across the United States, the challenge aimed to explore the power of the Internet and social networks in mobilizing large groups to solve difficult, time-critical problems [5]. The winning team, from MIT, located all of the balloons within nine hours [19] using a recursive incentive mechanis $m$ that rewarded people for reporting balloons and for recruiting others to look for balloons [6]. Th is approach was inspired by the work of Dodds et al. [20], which emphasizes the importance of individual financial incentives [21]. Cebrian and colleagues proved that MIT's incentive scheme is optimal in terms of minimizing the investment to recover information [22], and that it is robust to misinformation [23].

The DARPA Network Challenge seeded broad interest in the role of social networks in homeland security [24]. This led to a follow-up contest called the Tag Challenge from the U.S. Department of State [7], in which the task was to find five people across five cities and two continents within twelve hours [25]. The winning team found three of the five people and used an incentive scheme similar to the one that won the Network Challenge. Private firms and universities have also explored the potential of crowd mobilization. In 2009, Wired Magazine launched the Vanish Challenge [26] and in 2012, the University of Pennsylvania launched the MyHeartMap Challenge. The latter challenge saw over 300 participants who found and catalogued over 1,500 defibrillators in Philadelphia County [8]. However, to the best of our knowledge, there has not yet been any social mobilization contest with a focus on a developing country. There is a need to explore the landscape of crowd mobilization in developing countries and to identify the differences from crowd mobilization strategies observed in the developed world.

Researchers have also studied the potential and limitations of crowdsourcing in developing regions. Platforms such as txtEagle [27] and mClerk [28] aim to enable workers to earn supplemental income on low-end mobile phones. Others have examined the usage [29, 30] and non-usage [31] of Mechanical Turk in India, where approximately one third of Turkers reside. Efforts such as Ushahidi [32] and Mission 4636 in Haiti [33] have leveraged crowd workers to respond to crises in developing countries. Researchers have also explored the role of social networks such as Facebook [34] and SMS GupShup [35] in low-income environments. 


\section{The Whodunit Challenge}

The Whodunit Challenge was an India-wide social mobilization contest that awarded 100,000 Rupees (USD 1,667) to the winner. The objective of the challenge was to understand mechanisms, incentives and mediums people in India use to mobilize large groups of people for a time-bounded task.

\subsection{Design Principles}

The Whodunit Challenge embodied three design principles to make it broadly accessible throughout India. In India, $72 \%$ of the adult population is illiterate in English [36]. Thus, we localized the SMS messages by translating them into ten regional languages of India, making them more accessible than contests based on English alone. To ensure that the messages were not distorted in the translation, the translations were done by native speakers of local languages who were highly skilled in English. A majority of the Indian population has constrained access to modern devices and networks: the smartphone penetration is only $10 \%$ [37] and Internet penetration is $20 \%$ [38]. Thus, we aimed to enable participation by owners of basic mobile phones, thereby ruling out any dependence on computers, smart phones, or Internet connections (broadband or mobile). While Internet access could still offer advantages to participants, it was not strictly necessary to compete and win. A round $60 \%$ of the Indian population earns less than US\$2 per day [39]. Thus, we aimed to minimize the costs of participation. To participate in the contest, users needed to send a missed call from a mobile phone (which incurs no cost to them). To submit a phrase, they needed to send an SMS; this costs at most US\$0.015, though is free under many mobile subscription plans. Our design did not require users to initiate any voice calls, as this expense could have thwarted participation from cost-sensitive groups.

\subsection{Contest Mechanics}

The challenge required participants to reconstruct a secret sentence consisting of five pieces of information - Who, What, Where, When and Why (see Figure 1). Each piece of information was referred to as a phrase and represented a part of the secret sentence.

To receive a phrase, participants simply sent a missed call to the contest phone number. On receiving the call, our server responded with an SMS containing one of the five phrases. Each phrase was sent in two languages: English and the predominant local language in the telecom circle from which the call was made. The first person to forward all five phrases (i.e., the secret sentence) to our server via SMS was declared the winner. User responses were passed through a transliteration API, providing robustness to any minor typos incurred in re-typing phrases. 


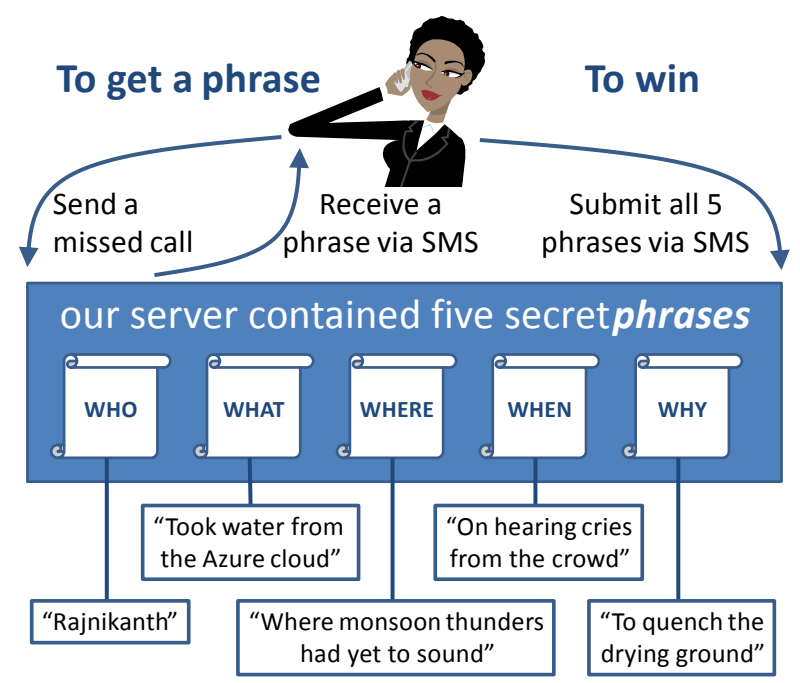

Figure 1. Graphical illustration of the Whodunit Challenge

What made the challenge difficult is that some phrases were very rare, thereby requiring participants to form large teams to gather all the phrases. Also, we made it difficult for any one person to receive many phrases by sending only a single phrase to each phone number even if we received multiple missed calls from the same number. Regulations in India make it difficult for a person to obtain many phone numbers; for example, VoIP DID numbers are not available for sale (and our server ignored VoIP calls anyway). A lso, telecom operators offer a limited nu mber of SIMs per customer, and each requires several pages of paperwork and supporting documents (personal identification, proof of address, etc.). While we advised participants that a very large team would be necessary to win, the award itself was made to an individual. Thus, any sharing of the award within a team would need to be managed by a team leader.

While the Whodunit Challenge was framed in lighthearted terms, we intended for the search for phrases to closely mirror the search for serious time-sensitive information, such as missing persons, suspicious containers, counterfeit currencies, etc. By using electronic phrases instead of physical artifacts, we were able to monitor and control each step of the contest.

\subsection{Chance of Winning}

How large of a team was needed in order to win the challenge? We did not publicize this information broadly, though during one Q\&A session, we indicated that competitive teams would contain several hundred members. In response to each missed call, the server responded according to a weighted random function, returning Who, What, Where, When and Why with probability $89.4 \%, 10 \%, 0.2 \%, 0.2 \%$, and $0.2 \%$, respec- 
tively. Given these probabilities, the chance of winning as a function of team size is illustrated in Figure 2. To have a 50\% chance of winning, a team needed 789 people. However, depending on their luck, s maller or larger teams could also win. To have a $5 \%$ chance of winning, a team needed about 230 people; for a $95 \%$ chance of winning, a tea m needed about 2040 people. The probability of winning did not depend on participants' location, time of sending a missed call, or other factors, as each phrase was returned independently at random.

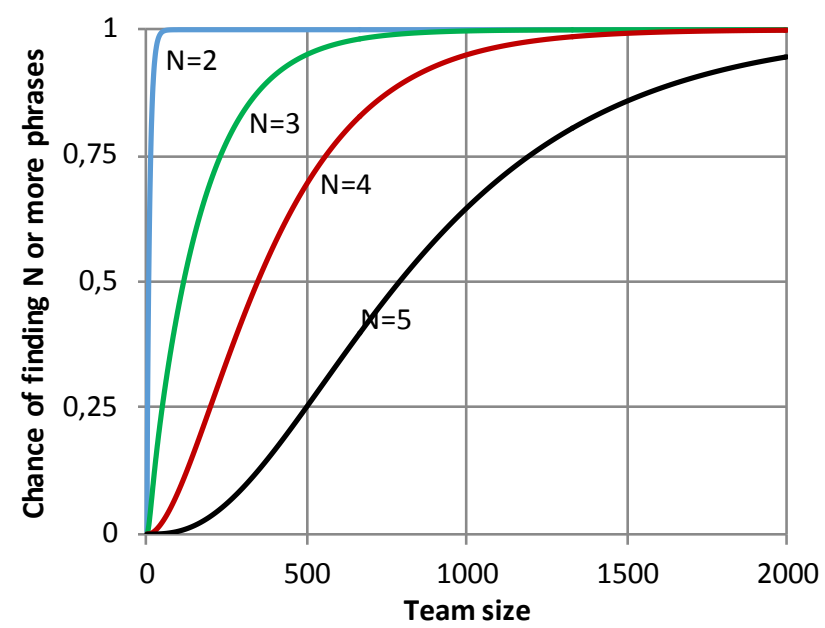

Figure 2. Chance of finding $\mathrm{N}$ or more phrases as a function of team size

\subsection{Publicity and Outreach}

We publicized the challenge widely in order to seed participation. A distinguished speaker announced the challenge to a live audience of 2,500 undergraduate engineering students about one week prior to the contest launch [40]. We conducted a large email and social media campaign targeting engineering colleges, MBA colleges, and student volunteers connected with Microsoft Research India. We also presented posters at two academic conferences in the month preceding the contest to create awareness among computer scientists. While the audiences for these activities were primarily composed of Internet users, we advised team leaders that outreach to non-Internet users would be highly advantageous for growing a large team and winning the challenge. Also, to seed visibility among non-Internet users, we met with a group of cab drivers and called ten group owners on SMS GupShup. Our outreach activities led to media coverage by both domestic and international outlets [41, 42]. The basic rules for the contest were explained in the digital promotional material and personal conversations. Internet users could also visit the contest website [43] for more detailed examples. 


\section{$4 \quad$ Analysis Methodology}

To understand the results of the challenge, we employed a mix of quantitative and qualitative methods. We kept electronic logs of all calls and SMS's submitted to our server, and analyzed the approximate geographic orig in of calls using the prefix of the telephone number [37]. On the qualitative side, we conducted structured phone interviews with 84 participants, probing themes such as how they came to learn about the challenge, who they told and how they communicated about it, and what was their strategy (if any) to win. The interviews were conducted in English and Hindi by the first author (male, age 28). Each phone interview lasted around 15 minutes. We took detailed notes during the interview and used open coding to analyze the data. Of the 84 people we interviewed, 65 we re students, 17 were employed in a private job, and 2 were homemakers. The specific participants interviewed were 31 people (of 32 participants) who submitted all five phrases; 1 person (out of 2) who submitted 4 phrases; 6 people (out of 6) who submitted 3 phrases; 38 people (out of 53) who received one of the rare phrases (where, when, or why); and 8 other participants.

At the end of the challenge, we also invited participants to complete a brief online survey. We publicized the survey via SMS and also on the contest website, and received about 300 responses in one day. Many questions in the survey were optional and thus, different questions were answered by a different number of users. There were 167 male and 46 female respondents. The average age of the respondents was 21.4 years $(s . d .=6.28)$. The respondents were from 42 universities and 5 organizations. Respondents included 174 students, 14 salaried employees, 2 professors, and 1 homemaker. The majority of the users had a feature phone or basic phone. Fifty-nine respondents heard about the challenge through an email sent by a friend, college authorities or professors, 58 heard through offline conversations with friends, relatives, professors and colleagues, 47 got the information through Facebook and websites, and the remainder heard about the challenge through text messages, offline promotional events, advertisements, and tasks on Amazon Mechanical Turk. Most respondents, 192, received Who, 27 received What, 4 received Where, 2 received Why and none received When. Sixty-one respondents reported discovering one phrase while 65, 24, 11 and 36 participants reported discovering two, three, four and five phrases respectively. Eleven respondents could not even begin their campaign as the challenge finished much earlier than they expected. On an average, each person reported sharing their phrase with 33 people $($ s.d.=120) and receiving a phrase from 30 people (s.d.=93).

\section{$5 \quad$ Results}

The Whodunit Challenge was launched on February 1, 2013 at 9:00 AM local time. The challenge drew 7,739 participants in less than 15 hours (see Figure 3). The first winning submission was made in just over 5 hours. However, we delayed announcing that the contest was over until the evening, as we also wanted to rank and recognize the runner-up teams. 


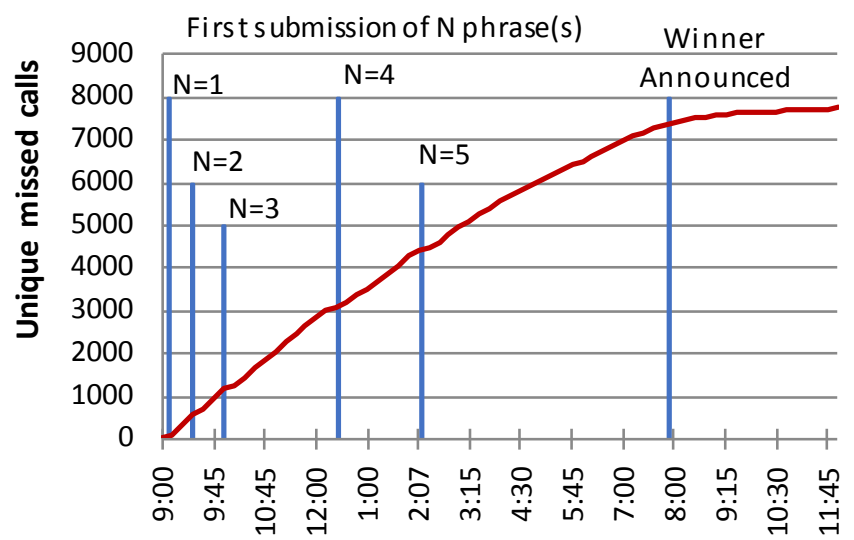

Figure 3. Number of unique missed calls vs. time

Participants sent a total of 10,577 missed calls to the system. Of the unique callers, 6,980 received the phrase for "Who"; 740 received "What"; 18 received "Where", 17 received "When" and 17 received "Why".

There were 185 people who submitted at least one phrase. The first person to submit two phrases did so within 26 minutes; 3 phrases, within 57 minutes; 4 phrases, within 3 hours and 19 minutes; and five phrases (winning the contest) after 5 hours and 7 minutes. Geographically, participation spanned across all of India, as illustrated in Figure 4.

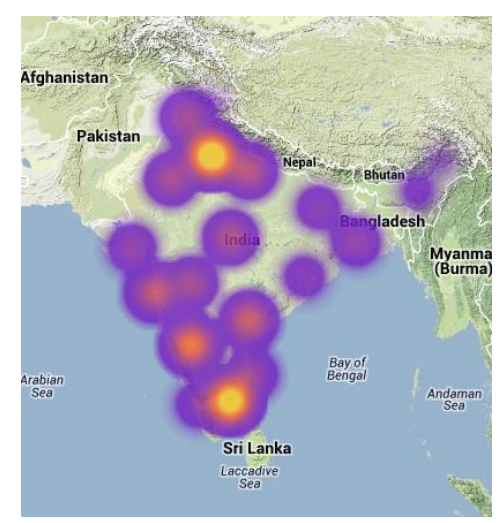

Figure 4. Heat map of received missed calls

\subsection{Winning Strategies}

The winning teams are listed in Table 1 . The table lists all 20 teams who submitted 3 or more phrases and, to the best of our knowledge, discovered these phrases without 
help from other teams. While we are certain about the rank ordering of the first two teams, there is a complication in ranking the remain ing teams: the winning team posted all of the phrases on the Facebook page of Whodunit Challenge at 4:30pm. Thus, we rank teams by two criteria: first, by the number of phrases they submitted in advance of $4: 30 \mathrm{pm}$, and second, by the total number of phrases they submitted and claimed (during our interview) to have found independently. While 13 teams claimed to have found all the phrases on their own, only 2 teams found all phrases in advance of the leak.

Table 1. Top 20 teams in the Whodunit Challenge

\begin{tabular}{|c|c|c|c|c|c|c|c|c|c|c|c|c|}
\hline 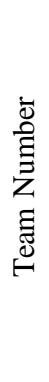 & $\frac{.00}{.00}$ & 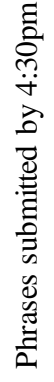 & 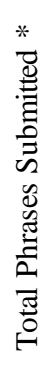 & 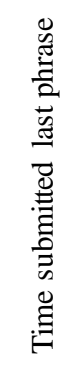 & 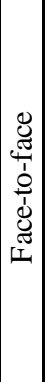 & 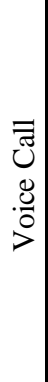 & $\sum_{n}^{\infty}$ & 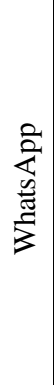 & 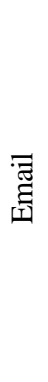 & 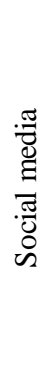 & 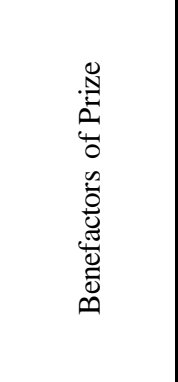 & $\begin{array}{l}\mathscr{0} \\
\dot{0} \\
z\end{array}$ \\
\hline 1 & $\begin{array}{c}\text { IIIT Delhi } \\
\text { (1) }\end{array}$ & 5 & 5 & $\begin{array}{l}2: 07 \\
\mathrm{PM}\end{array}$ & & $\checkmark$ & $\checkmark$ & $\checkmark$ & & $\checkmark$ & $\begin{array}{l}\text { published } \\
\text { incentive } \\
\text { scheme } \\
\end{array}$ & \begin{tabular}{|c} 
used SMS server; \\
Facebook group of \\
474 \\
\end{tabular} \\
\hline 2 & $\begin{array}{l}\text { IIT Delhi } \\
\text { (1) }\end{array}$ & 5 & 5 & $\begin{array}{l}2: 14 \\
\text { PM }\end{array}$ & & $\checkmark$ & $\checkmark$ & & & $\checkmark$ & $\begin{array}{c}\text { team leaders } \\
\text { only }\end{array}$ & $\begin{array}{l}\text { mostly used voice, } \\
\text { SMS to reach to } \\
\text { friends \& family }\end{array}$ \\
\hline 3 & $\begin{array}{l}\text { IIT Delhi } \\
\text { (2) }\end{array}$ & 4 & 5 & $\begin{array}{l}5: 00 \\
\mathrm{PM}\end{array}$ & & & & & & $\checkmark$ & $\begin{array}{c}\text { published } \\
\text { incentive } \\
\text { scheme } \\
\text { (see text) }\end{array}$ & $\begin{array}{l}\text { website with } 200 \\
\text { registrations; } \\
\text { FB event with } 392 \\
\text { replies }\end{array}$ \\
\hline 4 & $\begin{array}{c}\text { Jansons } \\
\text { Inst. of } \\
\text { Tech. } \\
\end{array}$ & 4 & 5 & $\begin{array}{l}\text { 7:00 } \\
\text { PM }\end{array}$ & & $\checkmark$ & $\checkmark$ & & & $\checkmark$ & $\begin{array}{c}\text { shared with } \\
\text { team (details } \\
\text { unclear) } \\
\end{array}$ & $\begin{array}{c}50 \% \text { reached via } \\
\text { SMS, voice; } 50 \% \\
\text { via FB }\end{array}$ \\
\hline 5 & $\begin{array}{c}\text { Paavai } \\
\text { Eng. Col- } \\
\text { lege }\end{array}$ & 4 & 4 & $\begin{array}{l}3: 30 \\
\mathrm{PM}\end{array}$ & $\checkmark$ & $\checkmark$ & $\checkmark$ & & & $\checkmark$ & $\begin{array}{c}\text { team leaders } \\
\text { only }\end{array}$ & $\begin{array}{l}2 \text { leaders managed } \\
7 \text { sub-teams of } 15- \\
20 \text { each }\end{array}$ \\
\hline 6 & $\begin{array}{l}\text { IIIT Delhi } \\
\text { (2) }\end{array}$ & 3 & 5 & $\begin{array}{l}7: 05 \\
\mathrm{PM}\end{array}$ & & $\checkmark$ & & & & & $\begin{array}{c}\text { team leaders } \\
\text { only }\end{array}$ & $\begin{array}{c}\text { leaders focused on } \\
\text { different geogra- } \\
\text { phies }\end{array}$ \\
\hline 7 & $\begin{array}{l}\text { IIIT Delhi } \\
\text { (3) }\end{array}$ & 3 & 3 & $\begin{array}{l}2: 10 \\
\text { PM }\end{array}$ & & $\checkmark$ & $\checkmark$ & $\checkmark$ & $\checkmark$ & $\checkmark$ & $\begin{array}{c}\$ 180-\$ 270 \\
\text { for reporting } \\
\text { new phrase }\end{array}$ & $\begin{array}{c}\text { one-person team; } \\
\text { calls \& WhatsApp } \\
\text { worked best }\end{array}$ \\
\hline 8 & $\begin{array}{c}\text { IIM } \\
\text { Indore }\end{array}$ & 3 & 3 & $\begin{array}{l}2: 24 \\
\text { PM }\end{array}$ & & $\checkmark$ & $\checkmark$ & $\checkmark$ & & & $\begin{array}{c}\text { given to } \\
\text { leaders, who } \\
\text { distribute to } \\
\text { sub-teams }\end{array}$ & $\begin{array}{c}\text { focused on calls \& } \\
\text { SMS }\end{array}$ \\
\hline
\end{tabular}




\begin{tabular}{|c|c|c|c|c|c|c|c|c|c|c|c|c|}
\hline 9 & $\begin{array}{l}\text { Delhi } \\
\text { Univ. }\end{array}$ & 3 & 3 & $\begin{array}{l}3: 18 \\
\mathrm{PM}\end{array}$ & & $\checkmark$ & $\checkmark$ & & & $\checkmark$ & \begin{tabular}{|c|} 
team leaders \\
and out-of- \\
state champi- \\
ons \\
\end{tabular} & $\begin{array}{c}\text { focused on calls, as } \\
\text { many do not read } \\
\text { SMS }\end{array}$ \\
\hline 10 & $\begin{array}{c}\text { VIT Chen- } \\
\text { nai }\end{array}$ & 2 & 5 & $\begin{array}{l}7: 07 \\
\mathrm{PM}\end{array}$ & & & $\checkmark$ & & & & $\begin{array}{c}\text { mostly lead- } \\
\text { ers; small } \\
\text { share (TBD) } \\
\text { with team }\end{array}$ & $\begin{array}{l}\text { used SMS exclu- } \\
\text { sively }\end{array}$ \\
\hline 11 & UPEI & 2 & 3 & $\begin{array}{l}5: 11 \\
\text { PM }\end{array}$ & $\checkmark$ & & $\checkmark$ & $\checkmark$ & & & $\begin{array}{c}\text { team leader } \\
\text { only }\end{array}$ & one-person team \\
\hline 12 & $\begin{array}{c}\text { LBS } \\
\text { Institute }\end{array}$ & 2 & 3 & $\begin{array}{l}5: 43 \\
\mathrm{PM}\end{array}$ & $\checkmark$ & & & & & & $\begin{array}{l}\text { donate to } \\
\text { college }\end{array}$ & $\begin{array}{c}\text { team leaders were } \\
\text { classmates }\end{array}$ \\
\hline 13 & $\begin{array}{l}\text { MIT Ma- } \\
\text { nipal }\end{array}$ & 0 & 5 & $\begin{array}{l}4: 59 \\
\text { PM }\end{array}$ & & & & $\checkmark$ & & & $\begin{array}{l}\text { team leaders } \\
\text { only }\end{array}$ & $\begin{array}{c}\text { relatives in } \\
\text { hometown spread } \\
\text { info to many }\end{array}$ \\
\hline 14 & Chandigarh & 0 & 5 & $\begin{array}{l}5: 45 \\
\text { PM }\end{array}$ & $\checkmark$ & $\checkmark$ & $\checkmark$ & & & & $\begin{array}{l}\text { team leaders } \\
\text { only }\end{array}$ & $\begin{array}{l}\text { mother/daughter } \\
\text { team; reached to } \\
\text { friends/fam }\end{array}$ \\
\hline 15 & \begin{tabular}{|c|} 
IIM \\
Ahmeda- \\
bad
\end{tabular} & 0 & 5 & $\begin{array}{l}\text { 6:01 } \\
\text { PM }\end{array}$ & $\checkmark$ & & & & $\checkmark$ & & $\begin{array}{l}\text { team leaders } \\
\text { only }\end{array}$ & $\begin{array}{l}\text { had classmates } \\
\text { make two calls: } \\
\text { local/home SIM }\end{array}$ \\
\hline 16 & $\begin{array}{l}\text { Class } 11 \\
\text { students }\end{array}$ & 0 & 5 & $\begin{array}{l}6: 54 \\
\text { PM }\end{array}$ & & & $\checkmark$ & & & & $\begin{array}{c}\text { team leaders } \\
\text { only }\end{array}$ & $\begin{array}{c}\text { main team leader is } \\
\text { junior in high } \\
\text { school }\end{array}$ \\
\hline 17 & $\begin{array}{c}\text { Amrita } \\
\text { School of } \\
\text { Engineer- } \\
\text { ing } \\
\end{array}$ & 0 & 5 & $\begin{array}{l}7: 00 \\
\text { PM }\end{array}$ & & & & $\checkmark$ & & $\checkmark$ & $\begin{array}{c}\text { sponsor in- } \\
\text { dustrial visit } \\
\text { for college }\end{array}$ & $\begin{array}{c}\text { leaders asked } \\
\text { friends to contact } \\
\text { friends at home }\end{array}$ \\
\hline 18 & $\begin{array}{l}\text { VIT Chen- } \\
\text { nai (2) }\end{array}$ & 0 & 5 & $\begin{array}{l}7: 48 \\
\mathrm{PM}\end{array}$ & & $\checkmark$ & $\checkmark$ & & & $\checkmark$ & \begin{tabular}{|c|} 
promised \\
party for team
\end{tabular} & $\begin{array}{c}\text { made voice calls to } \\
\text { explain contest } \\
\text { purpose }\end{array}$ \\
\hline 19 & $\begin{array}{c}\text { VIT Chen- } \\
\text { nai (3) }\end{array}$ & 0 & 5 & $\begin{array}{l}7: 54 \\
\mathrm{PM} \\
\end{array}$ & & $\checkmark$ & $\checkmark$ & & & $\checkmark$ & $\begin{array}{c}\text { promised } \\
\text { party for team }\end{array}$ & $\begin{array}{c}70 \% \text { reached via } \\
\text { FB; } 30 \% \text { via calls } \\
\text { and SMS }\end{array}$ \\
\hline 20 & Unknown & 0 & 4 & $\begin{array}{l}5: 32 \\
\text { PM }\end{array}$ & $\neq$ & $\neq$ & $\neq$ & $\neq$ & $\neq$ & $\neq$ & $\neq$ & $\neq$ \\
\hline
\end{tabular}

* We asked teams to report the total number of phrases that they submitted without help from other teams.

‡ Data not available

The winning team was based at the Indraprastha Institute of Information Technology Delhi (IIIT Delhi), led by 2 Ph.D. students and 6 undergraduates. In advance of the contest launch, this team set up a website ${ }^{3}$ and a Facebook group ${ }^{4}$ that attracted 474 members. The website publicized the following financial incentives. If the team won, they would award Rs. 10,000 (USD 167) to anyone who sent them a new

\footnotetext{
3 http://muc.iiitd.edu.in/whodunit/

4 https://www.facebook.com/groups/528552907178873/
} 
phrase; Rs. 2,000 (USD 33) to anyone who directly referred someone who sent a new phrase, and a mobile top-up worth Rs. 50 (USD 0.83) to the first 200 people who sent any phrase. They set up an SMS server to which people could forward phrases. They recruited team members using a variety of methods, spanning phone calls, SMS, Whats App and social media platforms.

The second-place team was based at the Indian Institute of Technology Delhi (IIT Delhi), led by eight second year Computer Science undergraduates. This team finished just 7 minutes behind the leader. Yet they used a very different strategy: they set up a small call center, relying mostly on direct calls and SMS to reach out to family and friends who live in smaller towns and villages across the country. In turn, they asked these contacts to gather team members from the local community. One team member also set up a Facebook group and utilized Facebook group chat.

The third-place team was also based at IIT Delhi, led by six undergraduate students. This team found 4 phrases in advance of $4: 30 \mathrm{pm}$, and claims to have found the fifth phrase (working independently) by 5:00p m. Unlike other teams, this team relied solely on social media and email to recru it me mbers. They invited over 4,000 people to a Facebook event ${ }^{5}$, of whom 329 replied with "Going" and 63 replied with "May$b e$ ". The group page was lin ked to another website where team members could reg ister and receive a unique ID, which could be used to refer others to the team. Participation by those referred led to modest payments to the referrer (Rs. 100, or USD 1.67, for 20 referrals).

The fourth-place team, based at the Jansons Institute of Technology in Coimbatore, was led by a single undergraduate student. She estimated that she reached out to 250300 people, half via SMS and voice calls, and half via Facebook. She submitted the fourth phrase at 3:30 pm and the fifth at 7:00pm. While she expressed interest in sharing the prize money with team members, she did not have any incentive structure in place and the terms were not discussed with the team members; her team members helped her as a personalfavor rather than for a monetary incentive.

The fifth-place team was based at Paavai Engineering College in Tamil Nadu, led by two cousins. They managed seven sub-teams with 15-20 people per team and used face-to-face interactions, phone calls, SMS, and social networks to coordinate. Interestingly, they also contacted a relative who worked at a mobile shop; the shop asked customers to give a missed call on the contest number and forward phrases to him, which he then shared with the team leaders. They did not have a formal incentive strategy, though as they got closer to winning, they offered to share a prize with those who helped them.

\subsection{Emergent Themes}

Rather than describe additional teams in detail, we present three high-level themes that emerged across the remainder of our analysis. This draws from our interviews with teams, our interviews with recipients of rare phrases, and the web-based followup survey.

5 https://www.facebook.com/events/124800261025377 
Internet but also S MS, Voice, Face-to-Face. All of the top five teams (and 14 of the top 19) utilized the Internet to their advantage. The most common uses were to establish a website (either independently or as a Facebook page) and to reach out to friends and contacts via Facebook (10 teams), Whats App (6 teams) and email (2 teams).

At the same time, teams also demonstrated a heavy reliance on non-Internet technologies: thirteen teams utilized SMS and eleven utilized voice calls to mobilize people. There were nine teams that utilized all three technologies: SMS, voice calls, and the Internet. Only three teams relied on Internet technologies alone.

The prevalence of communications outside the Internet is confirmed by our interviews with those who received rare phrases. Most often, they heard about the contest via an SMS $(n=9)$ or face-to-face interaction $(n=8)$ with a friend. Learning about the contest from Facebook was less common $(n=4)$. Other ways of learning about the contest included email, phone calls, Whats App, etc. Our online survey revealed that even among participants that have access to various Internet-based services, $43 \%$ heard about the contest through offline personal conversations with friends and colleagues.

An example of effective use of non-Internet technologies is the runner-up team (IIT Delhi), who relied mainly on a call center approach to reach family members in rural India. As a team leader explained to us, "My mom doesn't use Internet", and neither does the majority of India's rural population, which constitutes $72 \%$ of the overall population. As another example, a team of office drivers used only voice calls to manage a team and found two phrases in less than two hours.

One enterprising undergraduate (from the Amrita School of Engineering, Coimbatore) claims to have built a team of 200 peers using face-to-face contact alone. He estimates that with the help of his team's combined efforts, he reached out to at least 1,000 people. While he reports finding three phrases, he did not submit them via SMS because he thought more phrases would be released later. (For this reason, his team does not appear in Table 1.).

These teams' success illustrates that it is also possible to mobilize a sizable crowd without broadcast technologies such as social media or Internet websites. This finding has implications for social mobilization in areas lacking Internet connectivity, or for well-connected areas that experience Internet outages during crises .

Reliance on Personal Networks. In previous social mobilization contests, many teams incentivized strangers to join them. However, in the Whodunit challenge, a common thread amongst many teams' strategies was a reliance on personal networks: team leaders reached out to their friends and family, as opposed to incentivizing les ser-known acquaintances or strangers to join their team. This is already evident in the strategies for teams 2, 4, and 5, described above, as well as for many other teams. This trend is also corroborated by the online survey where 63 respondents reported relying on friends and colleagues for discovering phrases rather than 16 respondents who incentivized strangers. We also collected anecdotes where participants simply borrowed their friends' phones and gave the missed call on their behalf, without even explaining that there was a contest. If a new phrase was received on the friend's phone, it would be forwarded to the participant's phone. Three recipients of rare 
phrases reported that their phone was borrowed and used in this way. One recipient of a rare phrase was a vegetable seller who had absolutely no knowledge about the contest; we hypothesize that his phone was borrowed without offering him any explanation.

Most Participants not Driven by Cash Rewards. Building on the prior theme, the primary motivation for most participants was a desire to help a friend or family me mber, rather than any desire for (or even knowledge about) a cash award. Of the top 19 teams, less than half had any plans to distribute the cash prize beyond the inner circle of team leaders; even the runner-up team did not offer any financial incentive to its members. In teams that did plan to distribute the prize, the ma jority were very vague about how they might reward their full team. In contrast to the challenges conducted in developed countries, team members were motivated by non-financial factors, and any reward offered to them would be perceived more as a courtesy than as an owed compensation for their services.

We can quantify this tendency based on our interviews with those who received a rare phrase. Of the 35 respondents, only about one quarter (9) said that they were told about any financial incentive in relation to the contest. The majority (18) were not told about incentives, while the remainder (8) were team leaders or individuals who were working alone. Of the people who were not told about any incentive scheme, the majority $(12 / 18)$ nonetheless shared their phrase with others. This fraction is not significantly different from those who shared their phrase with knowledge of an incentive scheme (7/9).

Some team leaders offered non-monetary incentives for their members. The leader of a team from A mrita School of Engineering, Coimbatore (\#17 in Table 1) promised to sponsor a forthcoming industrial visit for his class if they won the challenge. We talked to four team leaders who proposed to throw a party for their friends if they were the winner.

Participants sometimes had intrinsic motivation to participate. For example, one student who received a rare phrase and forwarded it to benefit the winning team (IIIT Delhi) remarked, "I knew about the incentive model. Money was not important. I wanted my institute to win." An Infosys employee chose to participate and forward a rare phrase to a friend's team because he thought the contest itself was creative and worthy of participation. He thought that the purpose of the contest was to understand the role of technology in solving crime.

Some teams also experimented with other incentives. One team (not shown in Table 1) approached a charitable foundation, asking them to help publicize their team in exchange for $75 \%$ of the prize money. While the foundation was receptive, it did not promptly post about the challenge on its Facebook page (which has over 20,000 likes) and thus offered little of the anticipated help within the timespan of the contest. 


\section{Discussion and Recommendations}

While the Whodunit Challenge was quite successful in attracting enthusiastic participants from across India, the lessons learned can also serve as design recommendations to help future crowd mobilization challenges to reach out to a larger number of people, especially in low-income or offline environments.

One of the shortcomings of the Whodunit Challenge was the low level of engagement by low-income low-literate populations, primarily because we did not promote the contest widely in offline environ ments. The contest and the prize money appeared to be too good to be true for many low-income people that we interacted with. Many of them were uncertain about the reasons for awarding a high monetary prize just for sending missed calls. Despite our explanations, they had reservations about whether they would be charged for sending a call to our system. They were also concerned whether we would misuse their number, e.g., by sending them pesky voice calls or text messages.

To encourage more participation by non-Internet users, one approach would be to restrict promotions to offline audiences, limiting the visibility to Internet users. Another approach would be to partner with local organizations that work closely with low-income groups, distribute graphic pamphlets in local languages, and conduct outreach efforts led by people who are from the target community or have similar socio-economic status. It could also help to make the contest harder, for example, by decreasing the frequency of certain phrases or enforcing geographical diversity of team members (in India, coarse-grained geographic information can be determined fro $m$ the caller ID [44]). As teams are forced to reach out to broader populations, they may derive greater benefit from reaching out to the masses of rural and lowerconnectivity residents. Disseminating phrases in audio format rather than text would also enable inclusion of lesser-educated participants, though the cost of phone calls could be a significant deterrent (either for participants or for the challenge organizers, depending on who pays for the calls.)

One of our interesting findings is that participants were often motivated by nonmonetary incentives, including social support for friends and recognition for their institution. Future challenges might employ non-monetary incentives to increase participation, for example, by offering recognition, goods or services that cater to groups (such as a party or travel vacation).

Our usage of mobile phone numbers as a unique personal identifier was largely successful in prompting the formation of large teams. However, it also led to some subtle implications, such as the practice of borrowing others' phones to leverage their participation without their full knowledge or consent. While we did not observe any serious abuses of this situation, e.g., by stealing phones or feeding misinformation to potential participants, these possibilities are nonetheless important to consider and guard against in future challenges.

One limitation in the design of the Whodunit Challenge is that it is not possible to know the exact sizes of teams. Addressing this limitation would have required a fundamental change in the contest dynamics, for example, to require each participant to identify themselves with one or more teams. This would likely require an interaction 
richer than a missed call, which would have added cost and complexity for partic ipants. Though sending SMS may seemeasy, only 185 of 7,739 participants submitted a phrase to our server. So me participants may have been motivated only to share their phrase with their team leader, while other participants may have had limited familiarity with SMS and how to forward them. In any case, finding creative techniques to more accurately track the growth and composition of teams, without adding complexity for participants, could yield large benefits in the analysis of future challenges. One potential approach could be to host a large number of contest phone numbers, each advertised to a small number of people. If two participants place calls on different numbers, it would be unlikely that they are on the same team.

Our final recommendation is to take extra care in designing simple rules and communicating them to participants. Though we distilled the challenge rules to very simple language, including several illustrative examples, many teams misunderstood as pects that prevented them from competing well. We found three teams who thought that some phrases would be released at a later date, preventing them from being aggressive in the in itial stages. We talked to five teams who assumed that phrases would be distributed across different geographical regions, causing them to seek out more geographies rather than seeking out more people. We also spoke with five teams who assumed that all phrases needed to be submitted together, preventing them from gaining feedback and recognition for intermediate progress. It is important to anticipate any possible misconceptions and proactively convey the requisite clarifications. Several individuals misunderstood each phrase to be a puzzle instead of a part of the secret sentence; for example, in response to "Who: Rajnikanth", they would respond with "actor". While these details are some what specific to the Whodunit Challenge, the broader implication is that though it is difficult, it is necessary to design simple rules that are easily understood and easily communicated from one person to another. This is especially important for lesser-educated participants and those who may lack the devices, connectivity or bandwidth to view large explanatory materials (such as websites, promotional videos, etc.). We also recommend setting up more accessible information portals, such as an Interactive Voice Response system, to make the rules more accessible for people with low literacy and limited access to the Internet.

\section{Conclusion}

This paper presents the first crowd mobilization challenge conducted in India, a developing-country context where effective social mobilization is broader and more inclusive than the rich-country settings studied previously. We customized the design of the challenge to incorporate local languages and to enable participation at very low cost by anyone with access to a basic mobile phone. The challenge was successful in attracting broad participation, spanning 7,700 participants from all across India in less than a day. While many participants utilized Internet technologies, we also found interesting usage of SMS, voice, and face-to-face communications that offered benefits in the Indian context. Unlike previous social mobilization contests, participants relied primarily on their personal networks, and often recru ited team members with- 
out offering any financial incentives. We synthesize our lessons learned as a set of recommendations to help future crowd mobilization challenges extend their reach into low-income, offline environments.

\section{$8 \quad$ References}

1. Von Ahn, L.: Duolingo: Learn a Language for Free While Helping to Translate the Web. Proceedings of the 2013 International Conference on Intelligent User Interfaces. pp. 1-2. ACM, New York, NY, USA (2013).

2. Bigham, J.P., Jay ant, C., Ji, H., Little, G., Miller, A., Miller, R.C., Miller, R., Tatarowicz, A., White, B., White, S., Yeh, T.: VizWiz: Nearly Real-time Answers to Visual Questions. Proceedings of the 23Nd Annual ACM Symposium on User Interface Software and Technology . pp. 333-342. ACM, New York, NY, USA (2010).

3. Chen, K., Kannan, A., Yano, Y., Hellerstein, J.M., Parikh, T.S.: Shreddr: Pipelined Paper Digitization for Low-resource Organizations. Proceedings of the 2Nd ACM Symposium on Computing for Development. pp. 3:1-3:10. ACM, New York, NY, USA (2012).

4. Hara, K., Le, V., Froehlich, J.: Combining Crowdsourcing and Google Street View to Identify Street-level Accessibility Problems. Proceedings of the SIGCHI Conference on Human Factors in Computing Systems. pp.631-640. ACM, New York, NY, USA (2013).

5. DARPA Network Challenge, http://archive.darpa.mil/net workchallenge.

6. Pickard, G., Pan, W., Rahwan, I., Cebrian, M., Crane, R., Madan, A., Pentland, A.: TimeCritical Social Mobilization. Science. 334, 509-512 (2011).

7. Rahwan, I., DSouza, S., Rutherford, A., Naroditskiy, V., McInerney, J., Venanzi, M., Jennings, N.R., Cebrian, M.: Global Manhunt Pushes the Limits of Social Mobilization. Computer. 46, 68-75 (2013).

8. MyHeartMap Challenge, http://www.med.upenn.edu/my heartmap/.

9. Wilcock, D.: Police "Facewatch" app targets London riot suspects, http://www.independent.co.uk/news/uk/crime/police-facewatch-app-targets-london-riotsuspects-7887778.html.

10. Crowdsourced videos, photos could aid Boston blast investigations, http://www.cnet.com/news/crowdsourced-videos-photos-could-aid-boston-blastinvestigations/.

11. Kaufman, L.: Bombings Trip Up Reddit in Its Turn in Spotlight, http://www.nytimes.com/2013/04/29/business/media/bombin gs-trip-up-reddit-in-its-turnin-spotlight.html, (2013).

12. Wemple, E.: Young men, please sue the New York Post, http://www.washingtonpost.com/blogs/erik-wemple/wp/2013/04/22/y oung-men-pleasesue-the-new-y ork-post/, (2013).

13. Telecommunications in India, http://en.wikipedia.org/w/index.php?title=Telecommunications_in_India\&oldid=6561391 85, (2015).

14. Census of India - Mode of Communication: 2001-2011, http://www.censusindia.gov.in/2011census/hlo/Data_sheet/India/Communication.pdf. 
15. GupShup Re-launches GupShup Messenger, Innovates for India, http://www.siliconindia.com/news/technology/GupShup-Relaunches-GupShupMessenger-Innovates-for-India-nid-140878-cid-2.html/1.

16. Indian Railways, http://en.wikipedia.org/w/index.php?title=Indian_Railways\&oldid=657313685, (2015).

17. Kumaraguru, P., Cranor, L.: Privacy in India: Attitudes and Awareness. In: Danezis, G. and Martin, D. (eds.) Privacy Enhancing Technologies. pp. 243-258. Springer Berlin Heidelberg (2006).

18. Kittur, A., Nickerson, J.V., Bernstein, M., Gerber, E., Shaw, A., Zimmerman, J., Lease, M., Horton, J.: The Future of Crowd Work. Proceedings of the 2013 Conference on Computer Supported Cooperative Work. pp. 1301-1318. ACM, New York, NY, USA (2013).

19. Tang, J.C., Cebrian, M., Giacobe, N.A., Kim, H.-W., Kim, T., Wickert, D. "Beaker": Reflecting on the DARPA Red Balloon Challenge. Commun ACM. 54, 78-85 (2011).

20. Dodds, P.S., Muhamad, R., Watts, D.J.: An experimental study of search in global social networks. Science. 301, 827-829 (2003).

21. Mason, W., Watts, D.J.: Financial Incentives and the "Performance of Crowds." Proceedings of the ACM SIGKDD Workshop on Human Computation. pp. 77-85. ACM, New York, NY, USA (2009).

22. Cebrian, M., Coviello, L., Vattani, A., Voulgaris, P.: Finding Red Balloons with Split Contracts: Robustness to Individuals' Selfishness. Proceed ings of the Forty -fourth Annual ACM Symposium on Theory of Computing. pp. 775-788. ACM, New York, NY, USA (2012).

23. Naroditskiy, V., Rahwan, I., Cebrian, M., Jennings, N.R.: Verification in Referral-Based Crowdsourcing. PLoS ONE. 7, e45924 (2012).

24. Ford, C.M.: Twitter, Facebook, and Ten Red Balloons Social Network Problem Solving and Homeland Security. (2011).

25. Rutherford, A., Cebrian, M., Dsouza, S., Moro, E., Pentland, A., Rahwan, I.: Limits of social mobilization. Proc. Natl. Acad. Sci. 110, 6281-6286 (2013).

26. Wired Magazine's Vanish Challenge, http://www.wired.com/vanish/2009/11/ff_vanish2.

27. Eagle, N.: Txteagle: Mobile Crowdsourcing. Proceedings of the 3rd International Conference on Internationalization, Design and Global Development: Held As Part of HCI International 2009. pp. 447-456. Springer-Verlag, Berlin, Heidelberg (2009).

28. Gupta, A., Thies, W.: mClerk: enabling mobile crowdsourcing in developing regions. CHI (2012).

29. Ipeirotis, P.: Demographics of Mechanical Turk. Presented at the NYU Center for Digital Economy Research Working Paper CeDER-10-01 March (2010).

30. Ross, J., Irani, L., Silberman, M.S., Zaldivar, A., Tomlinson, B.: Who Are the Crowdworkers?: Shifting Demographics in Mechanical Turk. CHI '10 Extended Abstracts on Human Factors in Computing Systems. pp. 2863-2872. ACM, New York, NY, USA (2010).

31. Khanna, S., Ratan, A., Davis, J., Thies, W.: Evaluating and Improving the Usability of Mechanical Turk for Low-income Workers in India. Proceedings of the First ACM Sy mposium on Computing for Development. pp. 12:1-12:10. ACM, New York, NY, USA (2010). 
32. Gao, H., Barbier, G., Goolsby, R.: Harnessing the Crowdsourcing Power of Social Media for Disaster Relief. IEEE Intell. Sy st. 26, 10-14 (2011).

33. Hester, V., Shaw, A., Biewald, L.: Scalable Crisis Relief: Crowdsourced SMS Translation and Categorization with Mission 4636. Proceedings of the First ACM Symposium on Computing for Development. pp. 15:1-15:7. ACM, New York, NY, USA (2010).

34. Wyche, S.P., Forte, A., Yardi Schoenebeck, S.: Hustling Online: Understanding Consolidated Facebook Use in an Informal Settlement in Nairobi. Proceedings of the SIGCHI Conference on Human Factors in Computing Systems. pp. 2823-2832. ACM, New York, NY, USA (2013).

35. Rangaswamy, N., Cutrell, E.: Re-Sourceful Networks: Notes from a Mobile Social Networking Platform in India. Pacific Affairs. 85, (2012).

36. Desai, S.B., Dubey, A., Joshi, B.L., Sen, M., Shariff, A., Vanneman, R.: Human Development in India: Challenges For a Society in Transition. (2010).

37. Meeker, M., Wu, L.: 2014 Internet Trends. KPCB.

38. Internet Live Stats, http://www.internetlivestats.com/internet-users/.

39. Poverty headcount ratio at $\$ 2$ a day (PPP) (\% of population), http://data.worldbank.org/indicator/SI.POV.2DAY.

40. Lee, P.: From Computing Research to Surprising Inventions.

41. Microsoft's social "Whodunit" competition to begin in India, https://in.news.y ahoo.com/microsofts-social-whodunit-competition-begin-india045205972.html.

42. Social whodunnit competition launches in India - tech - 31 January 2013 - New Scientist, http://www.newscientist.com/article/mg21729025.500-social-whodunnit-competitionlaunches-in-india.html.

43. The Whodunit? Challenge by Microsoft Research India, http://www.whodunitchallenge.com/.

44. Mobile telephone numbering in India, http://en.wikipedia.org/w/index.php?title=Mobile_telephone_numbering_in_India\&oldid= 657910549, (2015). 